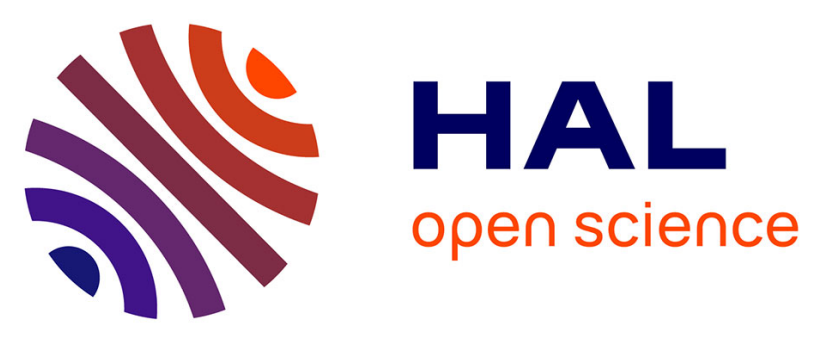

\title{
Ultrasmall Silica-Based Bismuth Gadolinium Nanoparticles for Dual Magnetic Resonance-Computed Tomography Image Guided Radiation Therapy
}

Alexandre Detappe, Eloise Thomas, Mark W Tibbitt I, Sijumon Kunjachan, Oksana Zavidij, Nishita Parnandi, Elizaveta Reznichenko, François Lux,

Olivier Tillement, Ross Berbeco

\section{To cite this version:}

Alexandre Detappe, Eloise Thomas, Mark W Tibbitt II, Sijumon Kunjachan, Oksana Zavidij, et al.. Ultrasmall Silica-Based Bismuth Gadolinium Nanoparticles for Dual Magnetic ResonanceComputed Tomography Image Guided Radiation Therapy. Nano Letters, 2017, 17 (3), pp.1733 1740. 10.1021/acs.nanolett.6b05055 . hal-01689566

\section{HAL Id: hal-01689566 https://hal.science/hal-01689566}

Submitted on 22 Jan 2018

HAL is a multi-disciplinary open access archive for the deposit and dissemination of scientific research documents, whether they are published or not. The documents may come from teaching and research institutions in France or abroad, or from public or private research centers.
L'archive ouverte pluridisciplinaire HAL, est destinée au dépôt et à la diffusion de documents scientifiques de niveau recherche, publiés ou non, émanant des établissements d'enseignement et de recherche français ou étrangers, des laboratoires publics ou privés. 


\title{
Ultrasmall Silica-Based Bismuth Gadolinium Nanoparticles for Dual Magnetic Resonance-Computed Tomography Image Guided Radiation Therapy
}

\author{
Alexandre Detappe ${ }^{\dagger, \ddagger, \S,}$, , Eloise Thomas ${ }^{\S}$, Mark W. Tibbitt $\|$, Sijumon Kunjachan ${ }^{\dagger, \ddagger}$, Oksana

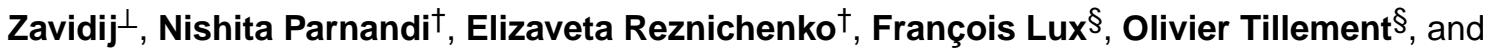 \\ Ross Berbeco ${ }^{\dagger}$, , ${ }^{*}$ \\ tDepartment of Radiation Oncology, Dana-Farber Cancer Institute, Harvard Medical School, \\ Boston, Massachusetts 02115, United States \\ ‡Department of Radiation Oncology, Brigham and Women’s Hospital, Boston, Massachusetts \\ 02115, United States \\ §Institut Lumière Matière, Université Claude Bernard Lyon 1, CNRS UMR5306, 69622 \\ Villeurbanne, France \\ "David H. Koch Institute for Integrative Cancer Research, Massachusetts Institute of Technology, \\ Cambridge, Massachusetts 02139, United States \\ ${ }^{\perp}$ Department of Medical Oncology, Dana-Farber Cancer Institute, Harvard Medical School, Broad \\ Institute at Harvard and MIT, Boston, Massachusetts 02142, United States
}

\section{Abstract}

\begin{abstract}
Selective killing of cancer cells while minimizing damage to healthy tissues is the goal of clinical radiation therapy. This therapeutic ratio can be improved by image-guided radiation delivery and selective radiosensitization of cancer cells. Here, we have designed and tested a novel trimodal theranostic nanoparticle made of bismuth and gadolinium for on-site radiosensitization and image contrast enhancement to improve the efficacy and accuracy of radiation therapy. We demonstrate in vivo magnetic resonance (MR), computed tomography (CT) contrast enhancement, and tumor suppression with prolonged survival in a non-small cell lung carcinoma model during clinical radiation therapy. Histological studies show minimal off-target toxicities due to the nanoparticles or radiation. By mimicking existing clinical workflows, we show that the bismuth-gadolinium nanoparticles are highly compatible with current CT-guided radiation therapy and emerging MR-
\end{abstract}

*Corresponding Authors: alex_detappe@dfci.harvard.edu. rberbeco@bwh.harvard.edu.

ORCID

Alexandre Detappe: 0000-0001-9364-1621

Mark W. Tibbitt: 0000-0002-4917-7187

Author Contributions

All authors contributed to the writing of this article and have approved the final version.

The authors declare no competing financial interest.

Supporting Information

The Supporting Information is available free of charge on the ACS Publications website at DOI: 10.1021/acs.nanolett.6b05055. Additional details on the synthesis of the nanoparticles, complexation of $\mathrm{Bi}^{3+}$ atoms, nanoparticle uptake study, toxicity evaluation, and radiation treatment plan. (PDF) 
guided approaches. This study reports the first in vivo proof-of-principle for image-guided radiation therapy with a new class of theranostic nanoparticles.

\section{Graphical abstract}

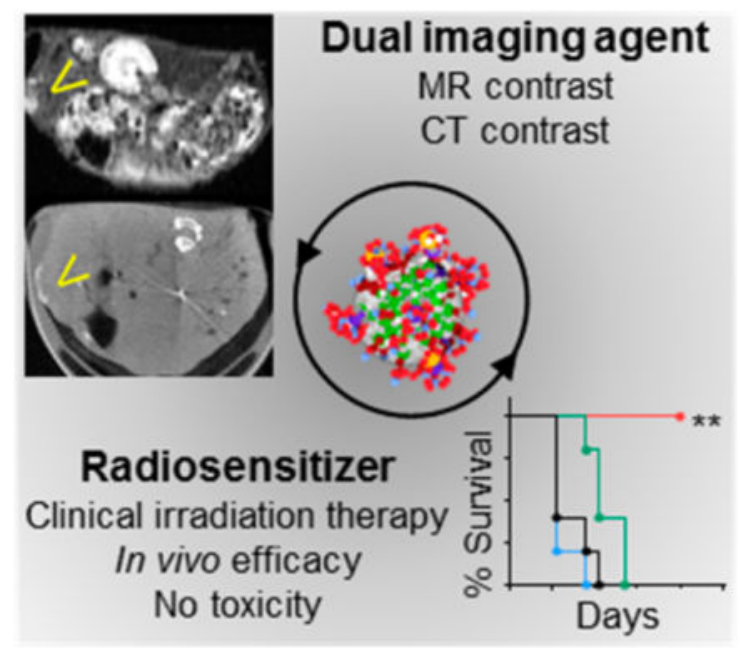

\section{Keywords}

Radiosentization; image-guided radiation therapy; bismuth; nanoparticle; nanomedicine

Clinical radiation therapy is a noninvasive means of killing cancer cells and effectively reducing tumor burden. This method of treatment is prescribed for more than $50 \%$ of cancer patients. Although radiation therapy is highly effective for the majority of cancer patients, ${ }^{1,2}$ the nonspecificity of irradiation can result in toxicity for surrounding tissues. ${ }^{3}$ This is especially problematic for patients with tumors that require high radiation doses or are difficult to target with image-guidance. ${ }^{4,5}$ For example, it has been demonstrated that dose escalation for non-small cell lung cancer (NSCLC) patients improves the overall survival but at the risk of toxicity in the lungs and heart. ${ }^{6-8}$ For centrally located early-stage NSCLC, proximity of the mediastinum can preclude the use of ablative radiation techniques like stereotactic body radiation therapy (SBRT). ${ }^{9}$ This is exacerbated by the large movements exhibited by some lung tumors due to respiration during therapy. ${ }^{10,11}$ Noninvasive imaging modalities can be used to improve the precision and the accuracy of clinical radiation treatment. ${ }^{12}$ To mitigate off-target toxicity, image-guided radiation therapy (IGRT) has been developed to localize tumors with cone-beam computed tomography (CBCT) images acquired just prior to the therapeutic irradiation. ${ }^{13}$ More recently, the use of magnetic resonance (MR) image-guided radiation therapy has enabled more-precise and accurate localization and treatment, especially for tumors embedded within soft tissues. ${ }^{14,15}$ Although these methods increase dose conformality to the target, some irradiation of healthy tissues is unavoidable.

Radiosensitizers have been developed to amplify the effects of radiation within tumor cells; however, some nontargeted chemical radiosensitizers have resulted in some severe 
toxicities. ${ }^{16,17}$ To solve this problem, high-atomic-number nanoparticles have been proposed as next-generation radiosensitizers or radiation-dose-amplification agents. These nanoparticles are only activated when irradiated. ${ }^{18}$ In this approach, photons from the clinical radiation beam interact with high-atomic-number atoms in the nanoparticles, generating secondary photoelectrons or Auger electrons, which deposit a local boost of energy (within a few microns of the nanoparticle). ${ }^{19,20}$ This induces biological stress in nearby cells and may also increase the local efficacy of the therapy. ${ }^{21}$ Coupling this novel therapy concept with quantitative volumetric image guidance will enable further optimization and individualization of radiation delivery to maximize therapeutic effect.

Looking toward clinical translation, focus should be put on nanoparticles that are compatible with clinical imaging techniques. Although many investigators have explored nanoparticles with optical agents, this modality is very limited clinically. ${ }^{22,23}$ To overcome this limitation, gadolinium-based nanoparticles have been designed and tested. ${ }^{24-26}$ Gadolinium atoms can provide both magnetic resonance imaging (MRI) contrast and radiation dose amplification. However, the probability for photoelectric interaction with a given atom is proportionate to $\mathrm{Z}^{3}$, where $\mathrm{Z}$ is the atomic number of the atom. Therefore, gadolinium $\left(\mathrm{Z}_{\mathrm{Gd}}=64\right)$ has a much lower probability of interaction than gold $\left(Z_{\mathrm{Au}}=79\right)$ or bismuth $\left(\mathrm{Z}_{\mathrm{Bi}}=83\right)$, for example. Investigators have exploited this property of bismuth in the design of nanoparticles for computed tomography $(\mathrm{CT})$ contrast and radiation sensitization. ${ }^{27-30}$ A shortcoming of previous studies of the latter application has been the use of low-energy photons that are not suitable for the vast majority of clinical radiation therapy procedures.

In the present study, we present a new theranostic nanoparticle that is suitable for MR and CT contrast as well as amplification of radiation dose under clinical irradiation conditions. This silica-based nanoparticle ( $\mathrm{SiBiGdNP}$ ) contains gadolinium and bismuth atoms that are sequestered by pendant DOTA ligands. The gadolinium atoms provide MRI $\mathrm{T}_{1}$ contrast, while both metals (gadolinium and bismuth) provide CT contrast. In addition, both the gadolinium and bismuth atoms enable radiation dose amplification (Figure 1A).

\section{Nanoparticle Characterization and in Vitro Proof of Concept}

The preparation of the silica-based bismuth-gadolinium nanoparticles (SiBiGdNP) was based on a top-down process leading first to the synthesis of a precursor polysiloxane core DOTA-Gd complex (Figure 1B and the Supporting Information). Afterward, the surface of the polysiloxane network was modified by grafting additional DOTA chelates to the surface followed by the complexation of $\mathrm{Bi}^{3+}$ ions. The attenuated total reflectance Fourier transform infrared, UV-vis absorbance, and high-performance liquid chromatography spectrum confirmed the complexation of the $\mathrm{Bi}^{3+}$ by the DOTA chelates on the nanoparticle (Figure S1). The choice of the DOTA as the complexation agent was made because of its high stability, as described by its $\log \mathrm{K}$ values, DOTA-Gd $=23.6^{31}$ and DOTA-Bi $=30.3{ }^{32}$

The hydrodynamic diameter $(4.5 \pm 0.9 \mathrm{~nm}$ ) of the nanoparticle (Figure 1C) is below the 10 $\mathrm{nm}$ kidney filtration threshold, minimizing potential off-target side effects. ${ }^{33}$ The $\zeta$ potential of the $\mathrm{SiBiGdNP}$ at $\mathrm{pH}=7$ was measured as $-3.6 \mathrm{mV}$. The polysiloxane base of the nanoparticle was covalently bound to an average of $~ 10$ DOTA ligands complexed with 
gadolinium atoms and an average of approximately five DOTA ligands complexed with bismuth atoms (Figure 1D). The absorbance measurements demonstrated that more than 95\% of the bismuth remains attached under physiological conditions during the period of greatest blood (Figure 1E). Cytotoxicity is measured in vitro $24 \mathrm{~h}$ post-incubation, with the nanoparticles at a concentration $\sim 30$ times higher than the in vivo injected dose $(420 \mathrm{mg} / \mathrm{kg})$ used in this study (Figure 1F). Phantom measurements of MRI and CT contrast demonstrated detectability down to a concentration of $0.1 \mathrm{mg} / \mathrm{mL}$ (Figure 1G). The SiBiGdNP acted as a $\mathrm{T}_{1}$ positive contrast agent with a longitudinal relaxivity $\left(r_{1}\right)$ and a transverse relaxivity $\left(r_{2}\right)$ measured, at $7 \mathrm{~T}$, to be $r_{1}=4.87 \mathrm{~s}^{-1} \mathrm{mM}^{-1}$ and $r_{1} / r_{2}=1.46$, which is slightly higher than other FDA-approved MR contrast agents. ${ }^{34}$ The CT contrast was measured as $4.26 \mathrm{HU} \mathrm{mM}^{-1}$, which is in the range of clinically used CT contrast agents. ${ }^{35}$

Both gadolinium $(Z=64)$ and bismuth $(Z=83)$ produced photoelectrons and Auger electrons when irradiated by clinical $6 \mathrm{MV}$ beam. ${ }^{18}$ This local radiation dose amplification was confirmed by an increase in $\gamma \mathrm{H} 2 \mathrm{AX}$ and 53BP1 foci $(P=0.001$ and $P<0.0001$, respectively) (Figure 2A,B). A significant increase in apoptosis was observed after coadministration of clinical radiation and $\operatorname{SiBiGdNP}(10.2 \pm 0.8 \%$ versus $8.9 \pm 5 \%, n=3, P$ $=0.047$ ) (Figure 2C,D). The effect combined treatment on clonogenic cell survival results in a dose enhancement factor of $1.99(P<0.001)$ (Figures $2 \mathrm{E}$ and S2).

\section{In Vivo Theranostic Applications}

Animal experiments were performed under protocols approved by the DFCI Institutional Animal Care and Use Committee (IACUC). To demonstrate in vivo efficacy, a fast-growing subcutaneous xenograft solid tumor model (A549 lung adenocarcinoma) was treated with clinical radiation therapy after intravenous administration of SiBiGdNP. In vivo experiments were performed with a timeline that mimics a typical clinical workflow (Figure 3A). The pharmacokinetics of SiBiGdNP were measured in blood samples over $24 \mathrm{~h}$, and the kinetic of the nanoparticles was assessed at $15 \mathrm{~min}$ and 3, 6, and $24 \mathrm{~h}$ post-injection by MRI and CT acquisitions (Figures 3B-D and S3).

Due to the tumor's fast growth and its poor vascularization, nanoparticles were still visible 6 $\mathrm{h}$ post-injection with $0.49 \%$ ID in the tumor (Figure S3). Accumulation was observed in kidneys, liver, and spleen (Figure 3C), with rapid clearance as expected on the basis of the small size of the nanoparticles. Only 0.39\% ID of the SiBiGdNP remained in the blood after $24 \mathrm{~h}$ (Figure 3D), and no organs other than the kidneys had more than $2 \% \mathrm{ID} 6 \mathrm{~h}$ postinjection (Figure 3C). Toxicity was assessed by hematoxylin and eosin (H\&E) staining of kidney, liver, spleen, and heart samples $24 \mathrm{~h}$ after systemic injection (Figure S4).

A radiation dosimetry study was performed based on an MR-guided radiation therapy clinical workflow. Organs were segmented on the MR images and then registered with the CT scan (Figure 3B) to calculate the radiation dose distribution, as is performed in the clinic for similar procedures (Figure 3E,F). Clinical treatment planning and radiation dose calculation software were used to simulate a single $10 \mathrm{~Gy}$ fraction delivered by a clinical linear accelerator (Varian Medical Systems, Inc.) (Figure S5). 
Therapeutic efficacy was studied with radiation therapy delivered at the time of maximum nanoparticle uptake in the tumor, as determined by the preceding imaging study. This timing was found to be 30 min post-injection (3.54\% ID) and was similar to that of a previous study ${ }^{24}$ conducted with nanoparticles of comparable size (Figures $3 \mathrm{C}$ and S3). A total of 10 $\mathrm{cm}$ of water-equivalent material was placed between the mice and the radiation source to provide clinically realistic scatter conditions (Figure S5). Body-weight was monitored postirradiation (Figure 4A) as one assessment of the safety of the treatment. To examine the long-term efficacy, a tumor growth (Figure 4B,C) and survival (Figure 4D) study was performed. Both control groups showed a rapid progression of the tumor burden with no mice surviving more than 70 days after therapy. Mice treated with $10 \mathrm{~Gy}$ irradiation only (no nanoparticles) showed a limited response during the first 30 days followed by rapid tumor growth, with no mice in this group surviving more than 80 days. The group treated with SiBiGdNP followed by radiation showed statistically significant improvement in both tumor growth delay $(P=0.045)$ (Figure 4B,C) and survival compared to the irradiation control group $(P=0.0059)$ (Figure 4D).

Damage to tumor and healthy tissues were evaluated by quantification of double-strand DNA breaks by $\gamma \mathrm{H} 2 \mathrm{AX}$ staining 30 min post-irradiation ${ }^{36}$ (Figure $5 \mathrm{~A}$ ). In the healthy tissues, no significant increase of DNA double-strand breaks was observed for the irradiated groups compared to both control (non-irradiated) groups. In the tumors, a significant increase in DNA damage was observed in the tumor when the irradiation was performed with $(89.33 \pm 14.3 \%)$ and without $\operatorname{SiBiGdNP}(67.31 \pm 11.36 \%)$ compared to the control groups $(8.1 \pm 4.3 \%$ and $5 \pm 1.3 \%$, respectively) (Figure $5 \mathrm{~B}$ ).

\section{Conclusions}

Radiation therapy is entering a new era with the emergence of new clinical concepts for image-guided radiation therapy (IGRT), exemplified by the recent commercial development of the MR-Linac. With these techniques, clinicians can image tumors during radiation delivery and modify the treatment beam accordingly.

The design, synthesis, and application of multifunctional nanoparticles provide a chemical route to complement the hardware advances in IGRT. Specifically, theranostic nano-particles that enable dual-modality tumor imaging and radiation-dose enhancement will provide clinicians with more options for precise tumor localization while mitigating toxicity in surrounding healthy tissue. In this vein, high-atomic-number nanoparticles have been developed that improve contrast during noninvasive imaging and amplify the radiation dose, enabling more accurate and effective cancer therapy, simultaneously.

Few nanotechnologies for radiation therapy have progressed to clinical trials. A hafnium colloid is under investigation for radiation-dose amplification following intratumoral injection (NCT01433068). Gadolinium NPs (NCT02820454) are being tested for MR imaging and radiation-dose amplification after systemic intravenous injection.

We have described a novel SiBiGdNP for dual-modality (MR and CT) contrast enhancement and clinical radiation dose amplification. The $\mathrm{Gd}$ atoms serve as a positive $\mathrm{MR} \mathrm{T}_{1}$ contrast 
agent, and the inclusion of $\mathrm{Gd}$ and $\mathrm{Bi}$ atoms enables $\mathrm{CT}$ imaging contrast. The synthesis of the SiBiGdNP employs a top-down process based on a silica construct bearing DOTA-Gd, which has been shown to be safe for routine intravenous injection. ${ }^{25,37}$ Surface modification with additional DOTA ligands enables the inclusion of gadolinium and bismuth atoms while remaining ultrasmall $(\sim 5 \mathrm{~nm})$. Experimental confirmation of safety and colocalization of $\mathrm{Bi}$ and Gd post administration indicates that the DOTA chelation strategy is effective in retaining these elements. Systemically administered SiBiGdNP provide significant in vivo radiation dose amplification, as demonstrated in vitro and in vivo during clinical radiation therapy delivery, resulting in greater tumor control and longer survival in mouse models of lung cancer.

\section{Methods}

\section{Silica-Based Bismuth-Gadolinium Nanoparticles}

The SiGdNP (no bismuth) nanoparticles were synthesized by a top-down process described by Mignot et al. ${ }^{38}$ (see the Supporting Information). Sodium hydroxide (NaOH, 99.99\%), hydrochloric acid ( $\mathrm{HCl}, 36.5-38 \%$ ), dimethyl sulfoxide (DMSO, > 99.5\%), and $\mathrm{BiCl} 3$ (>W98\%) were purchased from Aldrich Chemical. Acetonitrile (CH3CN, > 99.9\%) was purchased from Carlo Erba. Trifluoroacetic acid (TFA, > 99\%) was purchased from Alfa Aesar. Copper sulfate pentahydrate $\left(\mathrm{CuSO}_{4} \cdot 5 \mathrm{H}_{2} \mathrm{O}, 98 \%\right)$ was purchased from Merck. $\mathrm{Gd}$ and $\mathrm{Bi}(1000 \mathrm{mg} / \mathrm{mL} \pm 0.2 \%)$ ICP single element standard solutions were purchased from Carl Roth.

The derivative DOTA chelate $\left(2,2^{\prime}, 2^{\prime \prime}\right.$-(10-(2-((2,5-dioxopyrrolidin-1-yl)oxy)-2oxoethyl)-1,4,7,10-tetraazacyclododecane-1,4,7-triyl)triacetic acid) was purchased from ChemaTech (France). All products were used without further purification. Only Mili-Q water $(\rho>18 \mathrm{M} \Omega \cdot \mathrm{cm})$ was used for the aqueous solution preparation.

\section{Dynamic Light Scattering}

Direct dynamic light scattering (DLS) measurements of the hydrodynamic diameter distribution of the nanoparticles were performed via a Zetasizer NanoS DLS instrument (laser He-Ne $633 \mathrm{~nm}$ ) from Malvern Instruments. Lyophilized particles were first dispersed in water for $1 \mathrm{~h}$ at room temperature, $\left[\mathrm{Gd}^{3+}\right]=100 \mathrm{mM}$ and $\mathrm{pH}=7.4$. The nanoparticles were diluted to $\left[\mathrm{Gd}^{3+}\right]=10 \mathrm{mM}$, and measurements were taken immediately.

\section{Elemental Characterization}

The determination of the accurate concentration of gadolinium and bismuth in the nanoparticle was performed by inductively coupled plasma-optical emission spectroscopy (ICP-OES). The particles were degraded overnight in $5 \mathrm{~mL}$ of aqua regia $\left(\mathrm{HNO}_{3} 67 \%\right.$ mixed with $\mathrm{HCl} 37 \%(1 / 2 ; \mathrm{v} / \mathrm{v})$ at $80{ }^{\circ} \mathrm{C}$ and at an estimated concentration in gadolinium of 0.01 $\mathrm{mM}, 0.02 \mathrm{mM}$ or $0.05 \mathrm{mM}$. Subsequently, the samples were diluted to $50 \mathrm{~mL}$ with $0.5 \mathrm{M}$ $\mathrm{HNO}_{3}(1 / 2500, \mathrm{v} / \mathrm{v})$. The ICP-OES was calibrated with a single element standard solution prepared from $1000 \mathrm{ppm}$ Gd standard and $1000 \mathrm{ppm}$ Bistandard by successive dilutions with an $\mathrm{HNO}_{3} 5 \%(\mathrm{w} / \mathrm{w})$ matrix. For each particle, the $\mathrm{Gd}^{3+}$ and $\mathrm{Bi}^{3+}$ composition given is an average of the three samples prepared (at $0.01,0.02$, and $0.05 \mathrm{mM}$ ). 


\section{Stability of the Nanoparticles}

The stability of the nanoparticles was determined by relaxometry measurements over $24 \mathrm{~h}$ in aqueous solutions with a $\mathrm{pH}$ solution of 5 and 7 , respectively. SiBiGdNP were dispersed in water at a concentration of $\left[\mathrm{Gd}^{3+}\right]=40 \mathrm{mM}$, and the $\mathrm{pH}$ was adjusted to 7 or 5 . The solution was kept at $37^{\circ} \mathrm{C}$ for all the experiments. Between 0 and $24 \mathrm{~h}$, the solution was diluted in water, and the absorbance spectra was recorded using a UV-vis spectrophotometer (Varian Cary50).

\section{NMR Measurements}

Relaxation time measurements were performed using a Bruker Biospec operating at a magnetic field of $7 \mathrm{~T}$ and at $37^{\circ} \mathrm{C}$. Before measurements of $T_{1}$ (longitudinal relaxation time) and $T_{2}$ (transverse relaxation time), lyophilized particles were dispersed in water for $1 \mathrm{~h}$ at room temperature, $[\mathrm{Gd}]=100 \mathrm{mM}$ and $\mathrm{pH}=7.4$. The SiBiGdNP $r_{1}=4.87 \mathrm{~s}^{-1} \cdot \mathrm{mM}^{-1}$ per $\mathrm{Gd}^{3+}$ and $r_{2}=3.48 \mathrm{~s}^{-1} \cdot \mathrm{mM}^{-1}$ per $\mathrm{Gd}^{3+}$. A similar experiment was performed with a $1 \mathrm{~T}$ MRI (nanoScan PET/CT Mediso scanner), showing $r_{1}=22.0 \mathrm{~s}^{-1} \mathrm{mM}^{-1}$ and $r_{1} / r_{2}=1.6$ (Figure S3).

\section{In Vitro DNA Double-Strand Breaks}

A549 NSCLC cells were incubated $30 \mathrm{~min}$ with SiBiGdNP at a concentration of $0.5 \mathrm{mM}$ prior to irradiation. Cells were fixed in $4 \%$ paraformaldehyde in PBS at room temperature for $15 \mathrm{~min}$. After fixation, cells were blocked in 1\% BSA, 10\% FBS, and 0.3\% tritonX-100 in PBS. Next, cells were stained with anti $\gamma \mathrm{H} 2 \mathrm{AX}$ antibody (Millipore) and anti-53BP1 (Santa Cruz) overnight. Subsequently, cells were incubated with secondary anti-mouse AlexaFluor-594 conjugated IgG and anti-rabbit AlexaFluor-488 conjugated IgG (Abcam), respectively, for the noted primary antibodies. A semiquantitative analysis was performed to evaluate the number of foci per cell expressing the $\gamma \mathrm{H} 2 \mathrm{Ax}$ and 53BP1 markers. Images were visualized with an upright Carl Zeiss microscope with an HXP 120C light source and a $63 x / 1.4$ oil plan-apochromat objective. Foci were identified in the images and their signal intensity was quantified using CellProfiler cell imaging software (version 2.1.1). ${ }^{39}$

\section{Pharmacokinetic Study in Plasma Samples}

A total of five mice were injected intravenously with $420 \mathrm{mg} / \mathrm{kg}$ (dry weight) of SiBiGdNP. Blood samples were collected at 5 and 30 min and 1, 3, 6, 24, and $48 \mathrm{~h}$ post-injection and analyzed with ICP-MS to determine the amount of bismuth and gadolinium per sample. Analysis was performed using a non-compartment model (Kinetica 4.4.1, Thermo Fisher).

\section{Biodistribution Study in Mice}

The biodistribution study was performed by ICP-MS in $n=6$ mice per time point after IV injection of $420 \mathrm{mg} / \mathrm{kg}$ (dry weight) $\mathrm{SiBiGdNP}$. The organs were dissolved in $\mathrm{HCl}, \mathrm{HNO}_{3}$, and $\mathrm{H}_{2} \mathrm{O}_{2}$ and analyzed on a VG Plasma Quad Excell ICP-MS. The experiment was performed at $30 \mathrm{~min}$ and 3, 6, and $24 \mathrm{~h}$ post-injection. This biodistribution study was then compared to a noninvasive imaging method (MR and CT) for the same time points (Figure S3). 


\section{In Vivo Imaging}

For the MRI study, a $T_{1}$ gradient echo sequence on an ASpect One-Touch MRI was used to track and quantify the amount of nanoparticles in the different organs. More specifically, a whole body acquisition with the following parameters was performed: echo time of $4 \mathrm{~ms}$, repetition time of $30 \mathrm{~ms}$, flip angle of $57^{\circ}$, and slice thickness of $0.5 \mathrm{~mm}$. For the $\mu \mathrm{CT}$ acquisition, a nanoScan PET/CT Mediso scanner was used. The acquisition parameters were: $45 \mathrm{kVp}$, exposure time of $1100 \mathrm{~ms}$, resolution of 12.8 pixels per $\mathrm{mm}$, and slice thickness of $0.08 \mathrm{~mm}$. Axial slides of the tumor were used to merge both CT and MRI images at the maximum concentration of nanoparticles in the tumor. The merged image was used for the dosimetry study to delineate the tumor region for irradiation.

\section{Dosimetry Study}

Clinical treatment planning and dose calculation software (Varian Medical Systems, Inc.) was used to calculate the 3D dose distribution in the animal. Animals were placed on top of $10 \mathrm{~cm}$ of solid water to mimic the depth in tissue of a typical tumor in the human body. On top of the tumor, $2 \mathrm{~cm}$ of tissue equivalent material was used to create backscatter. The irradiations were performed using the $6 \mathrm{MV}$ mode of a TrueBeamlinear accelerator (Varian Medical Systems, Inc.). The field size was equal to a $5.5 \mathrm{~cm}$ size in the $X$ direction $\left(X_{1}=0.5\right.$ $\mathrm{cm}$ and $\left.X_{2}=5 \mathrm{~cm}\right)$ and $10 \mathrm{~cm}$ in the $Y$ direction $\left(Y_{1}=Y_{2}=5 \mathrm{~cm}\right)$. The linear accelerator's primary collimators shielded the body of the mouse.

\section{Therapy Study in Mice}

Mice were randomly divided into four groups of five mice each: -SiBiGdNP/-IR; + $\mathrm{SiBiGdNP/-IR;-SiBiGdNP/+IR;} \mathrm{and} \mathrm{+SiBiGdNP/+IR.} \mathrm{The} \mathrm{mice} \mathrm{selected} \mathrm{with} \mathrm{SiBiGdNP}$ received a single intravenous injection of $420 \mathrm{mg} / \mathrm{kg}$ (dry weight) of nanoparticles $30 \mathrm{~min}$ prior to irradiation. Irradiations were performed with a single fraction of $10 \mathrm{~Gy}$ delivered with a $6 \mathrm{MV}$ photon beam from a Varian Truebeamlinear accelerator as mentioned above. Mice were included in the study as soon as the tumor reached $7 \mathrm{~mm}$ in the longer axis and were excluded when the tumor reached $3 \mathrm{~cm}$ in the longer axis. Tumor volume and survival studies were performed with these measurement criteria.

\section{In Vivo DNA Damage Study}

DNA damage was evaluated semi-quantitatively by $\gamma \mathrm{H} 2 \mathrm{AX}$ staining 30 min post-irradiation. Organs were harvested and fixed in $10 \%$ formalin followed by paraffin embedding. The staining was performed on tissue sections excised from the tumor, ipsilateral kidney, liver, spleen, lung, and heart. To quantify the toxicity by $\gamma \mathrm{H} 2 \mathrm{AX}$, a primary antibody Abcam ab26350 and secondary antibody, ser139 (Cell Signaling Technologies) was utilized. Images were analyzed using a Zeiss Axio microscope at $63 \times$ magnification. The number of nuclei positive for $\gamma \mathrm{H} 2 \mathrm{AX}$ were counted in $n=30$ images from three animals per group. The ratio of positive nuclei to total nuclei was used to determine the effect induced by the presence of the nanoparticles under irradiation in comparison with that of the control groups and of the irradiation-alone group. 


\section{Supplementary Material}

Refer to Web version on PubMed Central for supplementary material.

\section{Acknowledgments}

\section{Funding}

This project was supported, in part, by a JCRT Foundation Grant and by award no. R21 CA188833 from the National Cancer Institute (NCI). The content of this manuscript is solely the responsibility of the authors and does not necessarily represent the official views of the $\mathrm{NCI}$ or $\mathrm{NIH}$.

\section{References}

1. Miller KD, Siegel RL, Lin CC, Mariotto AB, Kramer JL, Rowland JH, Stein KD, Alteri R, Jemal A. Ca-Cancer J Clin. 2016; 66(4):271-89. [PubMed: 27253694]

2. Siegel RL, Miller KD, Jemal A. Ca-Cancer J Clin. 2016; 66(1):7-30. [PubMed: 26742998]

3. Barnett GC, West CM, Dunning AM, Elliott RM, Coles CE, Pharoah PD, Burnet NG. Nat Rev Cancer. 2009; 9(2):134-42. [PubMed: 19148183]

4. Movsas B, Hu C, Sloan J, Bradley J, Komaki R, Masters G, Kavadi V, Narayan S, Michalski J, Johnson DW, Koprowski C, Curran WJ Jr, Garces YI, Gaur R, Wynn RB, Schallenkamp J, Gelblum DY, MacRae RM, Paulus R, Choy H. JAMA oncology. 2016; 2(3):359-67. [PubMed: 26606200]

5. Kong FM, Ten Haken RK, Schipper MJ, Sullivan MA, Chen M, Lopez C, Kalemkerian GP, Hayman JA. Int J Radiat Oncol, Biol, Phys. 2005; 63(2):324-33. [PubMed: 16168827]

6. Hepel JT, Leonard KL, Safran H, Ng T, Taber A, Khurshid H, Birnbaum A, Wazer DE, DiPetrillo T. Brown University Oncology Research. Int J Radiat Oncol, Biol, Phys. 2016; 96:1021. [PubMed: 27745983]

7. Ramroth J, Cutter DJ, Darby SC, Higgins GS, McGale P, Partridge M, Taylor CW. Int J Radiat Oncol, Biol, Phys. 2016; 96(4):736-747. [PubMed: 27639294]

8. Brower JV, Amini A, Chen S, Hullett CR, Kimple RJ, Wojcieszynski AP, Bassetti M, Witek ME, Yu M, Harari PM, Baschnagel AM. Ann Oncol. 2016; 27(10):1887-94. [PubMed: 27502703]

9. Haseltine JM, Rimner A, Gelblum DY, Modh A, Rosenzweig KE, Jackson A, Yorke ED, Wu AJ. Pract Radiat Oncol. 2016; 6(2):e27-33. [PubMed: 26577006]

10. De Ruysscher D. Lancet Oncol. 2016; 17:1625. [PubMed: 27789197]

11. Bissonnette JP, Purdie TG, Higgins JA, Li W, Bezjak A. Int J Radiat Oncol, Biol, Phys. 2009; 73(3):927-34. [PubMed: 19095368]

12. Dawson LA, Menard C. Oncologist. 2010; 15(4):338-49. [PubMed: 20413639]

13. Jaffray DA, Siewerdsen JH, Wong JW, Martinez AA. Int J Radiat Oncol, Biol, Phys. 2002; 53(5): 1337-49. [PubMed: 12128137]

14. Dawson LA, Jaffray DA. J Clin Oncol. 2007; 25(8):938-46. [PubMed: 17350942]

15. Noel CE, Parikh PJ, Spencer CR, Green OL, Hu Y, Mutic S, Olsen JR. Acta Oncol. 2015; 54(9): 1474-82. [PubMed: 26206517]

16. Urtasun RC, Chapman JD, Band P, Rabin HR, Fryer CG, Sturmwind J. Radiology. 1975; 117(1): 129-33. [PubMed: 1162051]

17. Ning S, Bednarski M, Oronsky B, Scicinski J, Saul G, Knox SJ. Cancer Res. 2012; 72(10):2600-8. [PubMed: 22589277]

18. McMahon SJ, Paganetti H, Prise KM. Nanoscale. 2016; 8(1):581-9. [PubMed: 26645621]

19. Retif P, Pinel S, Toussaint M, Frochot C, Chouikrat R, Bastogne T, Barberi-Heyob M. Theranostics. 2015; 5(9):1030-44. [PubMed: 26155318]

20. McMahon SJ, Hyland WB, Muir MF, Coulter JA, Jain S, Butterworth KT, Schettino G, Dickson GR, Hounsell AR, O'Sullivan JM, Prise KM, Hirst DG, Currell FJ. Sci Rep. 2011; 1:18. [PubMed: 22355537] 
21. Pan Y, Leifert A, Ruau D, Neuss S, Bornemann J, Schmid G, Brandau W, Simon U, JahnenDechent W. Small. 2009; 5(18):2067-76. [PubMed: 19642089]

22. Kunjachan S, Detappe A, Kumar R, Ireland T, Cameron L, Biancur DE, Motto-Ros V, Sancey L, Sridhar S, Makrigiorgos GM, Berbeco RI. Nano Lett. 2015; 15(11):7488-96. [PubMed: 26418302]

23. Manohar N, Reynoso FJ, Diagaradjane P, Krishnan S, Cho SH. Sci Rep. 2016; 6:22079. [PubMed: 26912068]

24. Detappe A, Kunjachan S, Sancey L, Motto-Ros V, Biancur D, Drane P, Guieze R, Makrigiorgos GM, Tillement O, Langer R, Berbeco R. J Controlled Release. 2016; 238:103-13.

25. Sancey L, Kotb S, Truillet C, Appaix F, Marais A, Thomas E, van der Sanden B, Klein JP, Laurent B, Cottier M, Antoine R, Dugourd P, Panczer G, Lux F, Perriat P, Motto-Ros V, Tillement O. ACS Nano. 2015; 9(3):2477-88. [PubMed: 25703068]

26. Le Duc G, Miladi I, Alric C, Mowat P, Brauer-Krisch E, Bouchet A, Khalil E, Billotey C, Janier M, Lux F, Epicier T, Perriat P, Roux S, Tillement O. ACS Nano. 2011; 5(12):9566-74. [PubMed: 22040385]

27. Song G, Liang C, Gong H, Li M, Zheng X, Cheng L, Yang K, Jiang X, Liu Z. Adv Mater. 2015; 27(40):6110-7. [PubMed: 26331476]

28. Lee N, Choi SH, Hyeon T. Adv Mater. 2013; 25(19):2641-60. [PubMed: 23553799]

29. Aviv H, Bartling S, Grinberg I, Margel S. J Biomed Mater Res, Part B. 2013; 101(101):131-8.

30. Alqathami M, Blencowe A, Geso M, Ibbott G. J Biomed Nanotechnol. 2016; 12(3):464-71. [PubMed: 27280244]

31. Sherry AD, Brown RD, Geraldes CFG, Koenig SH, Kuan KT, Spiller M. Inorg Chem. 1989; 28(3): $620-622$.

32. Csajbok E, Baranyai Z, Banyai I, Brucher E, Kiraly R, Muller-Fahrnow A, Platzek J, Raduchel B, Schafer M. Inorg Chem. 2003; 42(7):2342-9. [PubMed: 12665368]

33. Choi HS, Liu W, Misra P, Tanaka E, Zimmer JP, Itty Ipe B, Bawendi MG, Frangioni JV. Nat Biotechnol. 2007; 25(10):1165-1170. [PubMed: 17891134]

34. Na HB, Lee JH, An K, Park YI, Park M, Lee IS, Nam DH, Kim ST, Kim SH, Kim SW, Lim KH, Kim KS, Kim SO, Hyeon T. Angew Chem, Int Ed. 2007; 46(28):5397-401.

35. Kao CY, Hoffman EA, Beck KC, Bellamkonda RV, Annapragada AV. Academic radiology. 2003; 10(5):475-83. [PubMed: 12755534]

36. Herter-Sprie GS, Korideck H, Christensen CL, Herter JM, Rhee K, Berbeco RI, Bennett DG, Akbay EA, Kozono D, Mak RH, Mike Makrigiorgos G, Kimmelman AC, Wong KK. Nat Commun. 2014; 5:5870. [PubMed: 25519892]

37. Kotb S, Piraquive J, Lamberton F, Lux F, Verset M, Di Cataldo V, Contamin H, Tillement O, Canet-Soulas E, Sancey L. Sci Rep. 2016; 6:35053. [PubMed: 27725693]

38. Mignot A, Truillet C, Lux F, Sancey L, Louis C, Denat F, Boschetti F, Bocher L, Gloter A, Stephan O, Antoine R, Dugourd P, Luneau D, Novitchi G, Figueiredo LC, de Morais PC, Bonneviot L, Albela B, Ribot F, Van Lokeren L, Dechamps-Olivier I, Chuburu F, Lemercier G, Villiers C, Marche PN, Le Duc G, Roux S, Tillement O, Perriat P. Chem - Eur J. 2013; 19(19):6122-36. [PubMed: 23512788]

39. Carpenter AE, Jones TR, Lamprecht MR, Clarke C, Kang IH, Friman O, Guertin DA, Chang JH, Lindquist RA, Moffat J, Golland P, Sabatini DM. Genome biology. 2006; 7(10):R100. [PubMed: 17076895] 
A. Healthy tissue

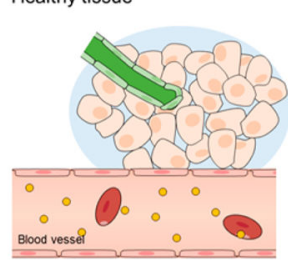

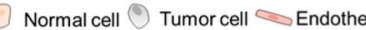

B.
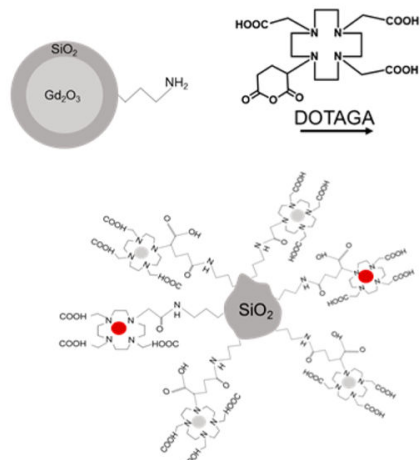

C.
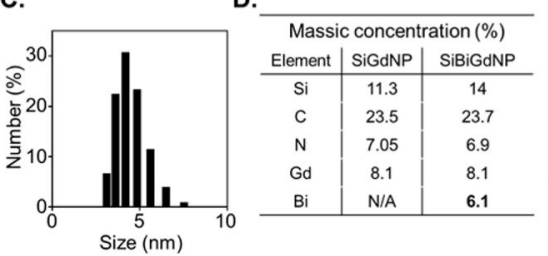

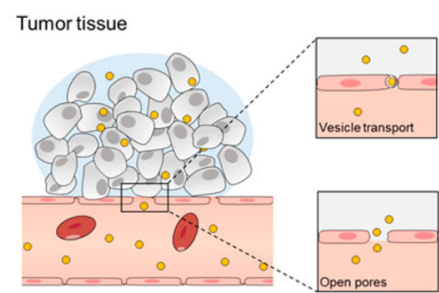

After irradiation

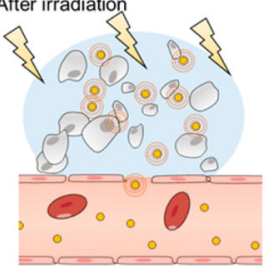

Physical radiation boost induced by SiGdNP

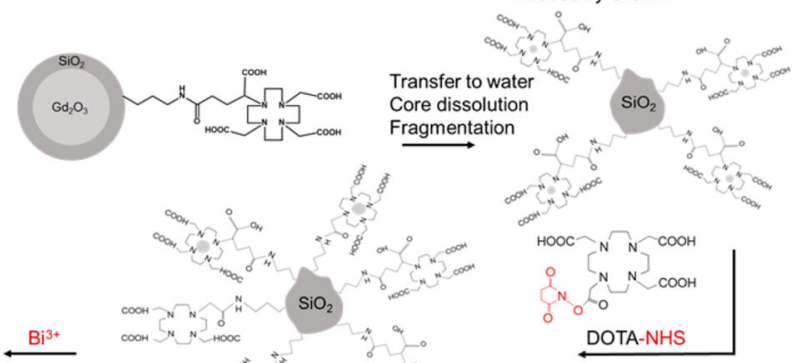

Figure 1.

Design and synthesis of SiBiGdNP. (a) Schematic representation of the SiBiGdNP uptake in a tumor and efficacy upon external radiation. (b) (Not to scale) The $\mathrm{Gd}_{2} \mathrm{O}_{3}$ core and its polysiloxane network are grafted to DOTAGA ligands before being transferred to water to dissolve the core. The final fragmentation into sub-5 $\mathrm{nm}$ silica-based gadolinium nanoparticles (SiGdNP) was then performed based on the method from Mignot et al. ${ }^{38} \mathrm{At}$ this stage of the synthesis, the $\mathrm{Gd}^{3+}$ atoms were complexed by the DOTAGA ligands. After, DOTA-NHS ligands were grafted to the surface to entrap free $\mathrm{Bi}^{3+}$ atoms into the final complex. (c) Dynamic light scattering measurements show a SiBiGdNP size of $4.5 \pm 0.9 \mathrm{~nm}$. (d) Elemental characterization by ICP-OES of the nanoparticle composition before and after the grafting of $\mathrm{Bi}^{3+}$. (e) Percent release of free $\mathrm{Bi}^{3+}$ atoms measured by absorbance $(305$ $\mathrm{nm}$ ) at $\mathrm{pH}=5$ and $\mathrm{pH}=7$ over $48 \mathrm{~h}$. (f) Toxicity of the SiBiGdNP as a function of the concentration $24 \mathrm{~h}$ post-incubation. (g) MRI (relaxivity) and CT (Hounsfield units) linear relation with concentration of nanoparticles (metal) in aqueous solution. 
A.
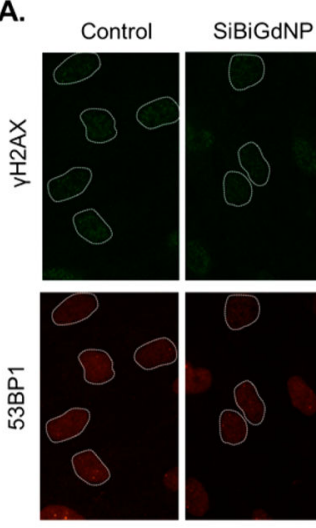

C.
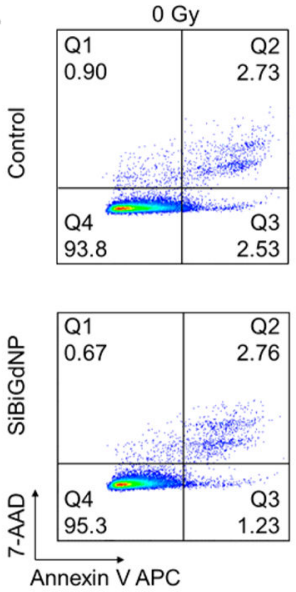

B.
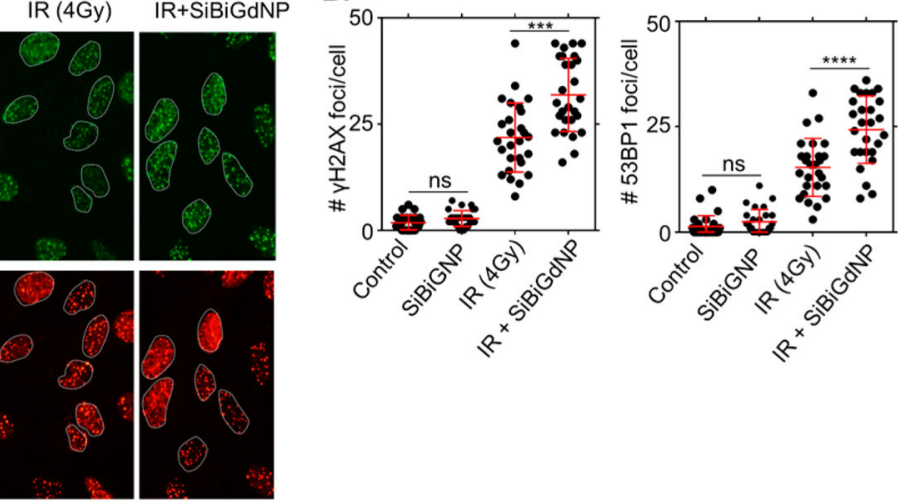

6 Gy
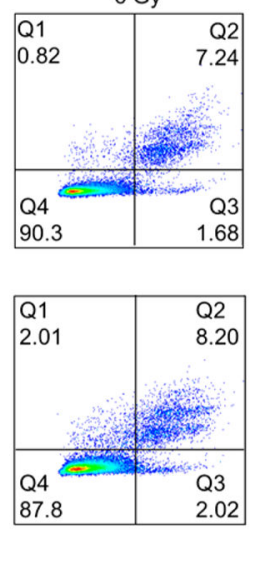

D.

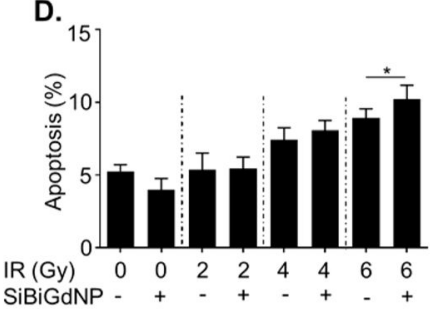

E.

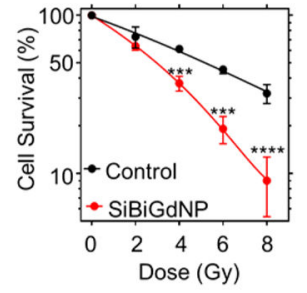

Figure 2.

In vitro radiation dose amplification by $\mathrm{SiBiGdNP}$ and clinical $6 \mathrm{MV}$ irradiation. (a) Qualitative representation of $\gamma \mathrm{H} 2 \mathrm{AX}$ and 53BP1 foci formation, with and without $4 \mathrm{~Gy}$ irradiation, with and without nanoparticles, 15 min post-irradiation. (b) Number of $\gamma \mathrm{H} 2 \mathrm{AX}$ foci and 53BP1 foci per cell $(n=3)$. (c) Qualitative flow cytometry data plot indicating the increase in apoptosis caused by the presence of SiBiGdNP under $6 \mathrm{MV}$ irradiation. (d) Results of the FACS study show the increasing apoptosis induced by SiBiGdNP and irradiation. (e) Clonogenic assay $(n=3)$ showing the long-term effect induced by the presence of the nanoparticles during irradiations. All data are represented as a mean \pm SD. $P$ values were calculated using two-tailed $t$ test. A single asterisk indicates $P<0.05$, three asterisks indicate $P<0.001$, and four asterisks indicate $P<0.0001$. 
A
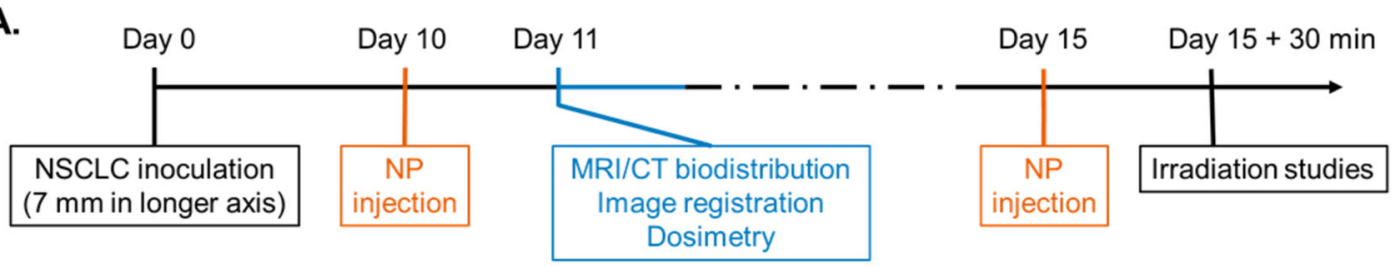

B.

C.
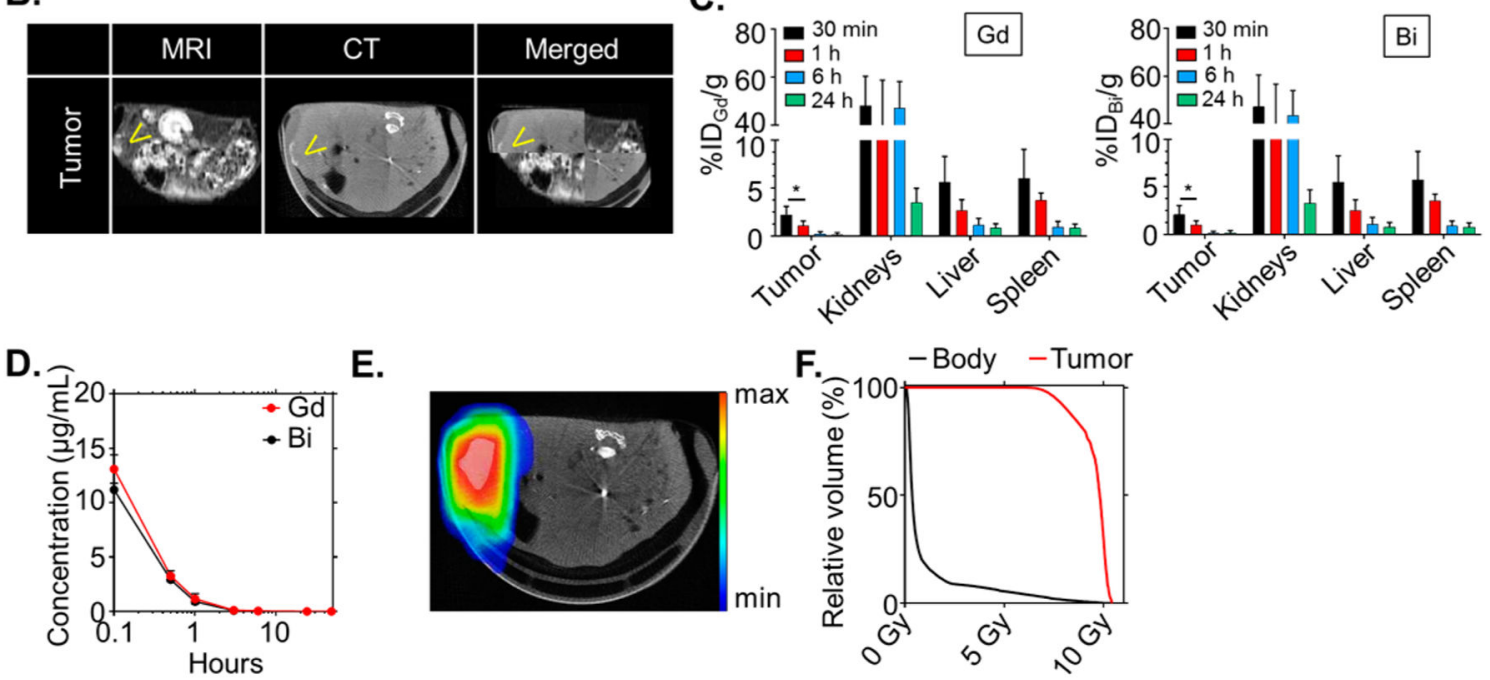

E.
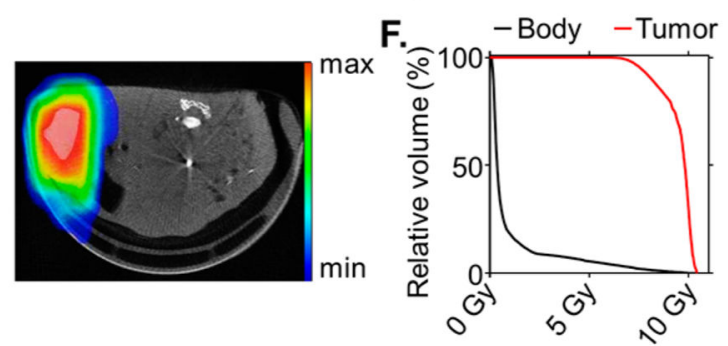

Figure 3.

Preclinical experimental workflow based on a clinical workflow. (a) Experimental timeline based on a current clinical workflow for MR-guided radiation therapy. (b) Fusion of the CT and MRI images. Yellow arrows indicate the increased contrast in the tumor. (c)

Biodistribution study performed by ICP-MS in six animals per time point after intravenous injection of $420 \mathrm{mg} / \mathrm{kg}$ of SiBiGdNP. Separate analysis of Bi and Gd shows strong colocalization in each organ. (d) Pharmacokinetic study $(n=5)$ of SiBiGdNP in blood samples. (e) Dosimetry study performed for a single fraction of $10 \mathrm{~Gy}$ irradiation delivered from a clinical linear accelerator (6 MV). (f) Dose-volume histogram showing the radiation dose distribution in the tumor and in the rest of the body. A single asterisk indicates $P<$ 0.05 . 


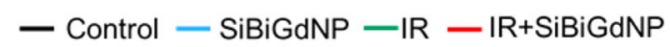

A.

B.
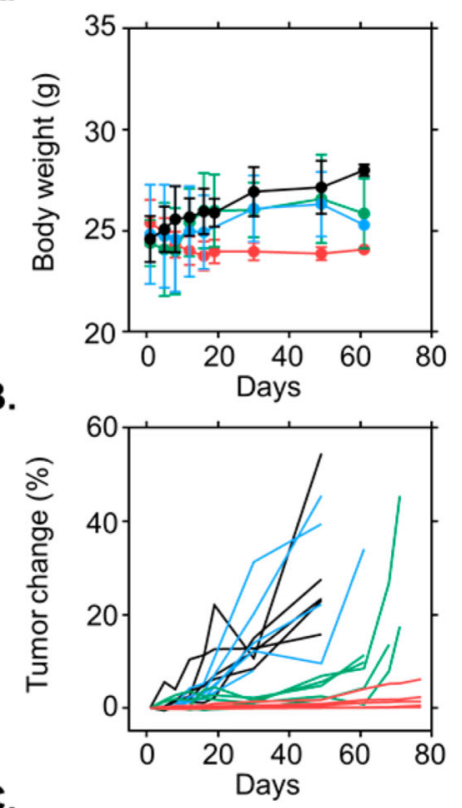

C.

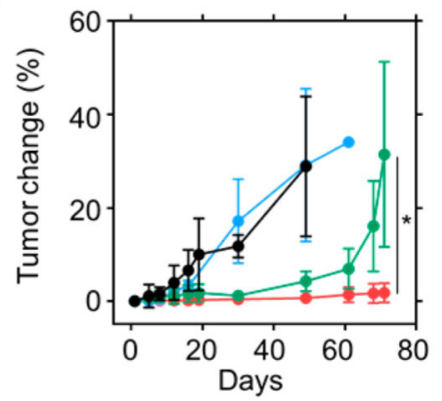

D.

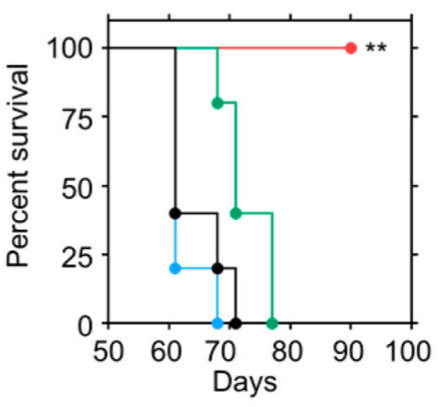

Figure 4.

In vivo therapeutic efficacy SiBiGdNP. (a) Body weight measurements demonstrate no gross toxicity. (b) Spider plot of the tumor size evolution as a function of time. (c) Mean tumor volume of each group ( $n=5$ per group). (d) Overall survival of each treatment cohort ( $n=5$ per group). All data are represented as a mean $\pm \mathrm{SD}$; a single asterisk indicates $P<0.05$, and two asterisks indicate $P<0.01$. 
A.

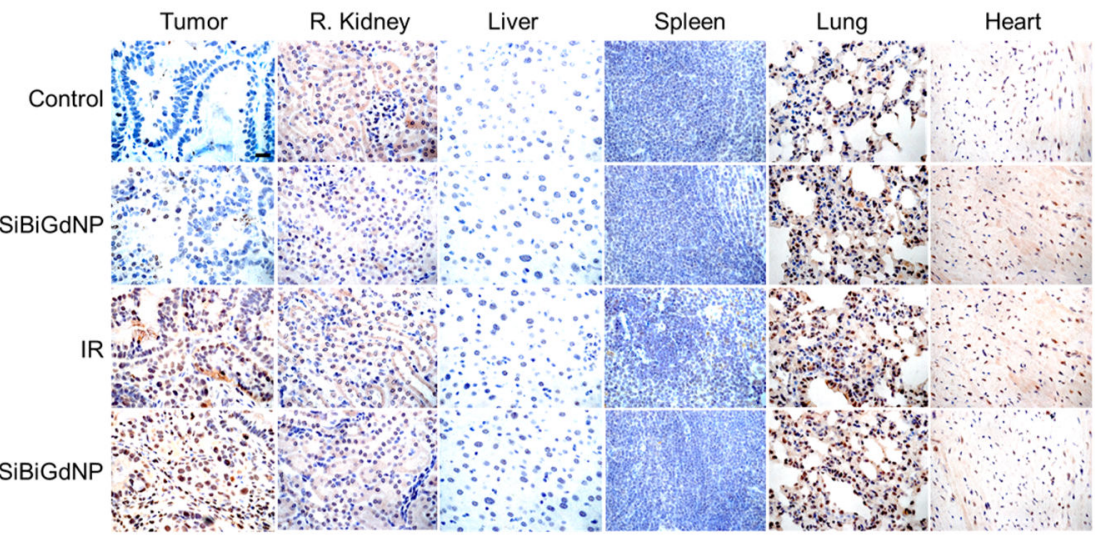

B.

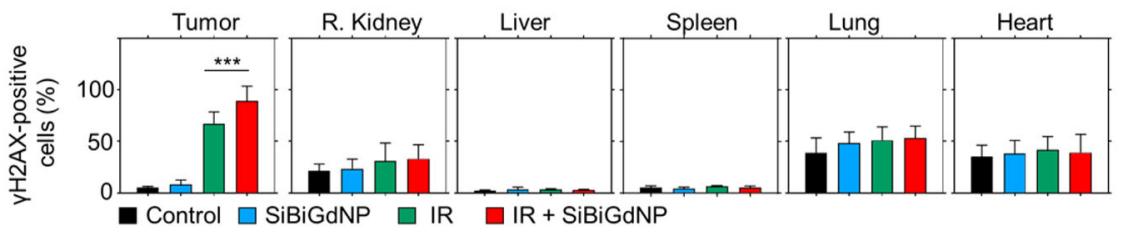

Figure 5.

Radiation-induced DNA damage study. (a) $\gamma \mathrm{H} 2 \mathrm{AX}$ staining representing the DNA doublestrand breaks in the tumor and healthy organs. Damaged cells are brown and viable cells are blue. Magnification 63x; scale bar $=20 \mu \mathrm{m}$. (b) The positive $\gamma \mathrm{H} 2 \mathrm{AX}$ cells were quantified across $n=30$ images randomly chosen ( $n=3$ per group). Data are shown as mean \pm STD. Triple asterisks indicate $P<0.001$. 